\title{
EVALUASI KARAKTERISTIK KUALITAS AIR DANAU LIMBOTO
}

\author{
Evaluation of Water-Quality Characteristics in Limboto Lake
}

\author{
Fitryane Lihawa dan Marike Mahmud \\ Pusat Studi Lingkungan dan Kependudukan, Universitas Negeri Gorontalo, Jl. Jend. Sudirman No. 6 Kota \\ Gorontalo 96128 - fitryane.lihawa@ung.ac.id
}

\begin{abstract}
This research aims at evaluating water-quality characteristics in Limboto Lake ecosystem in accordance with its designation. The research took place in Limboto Lake and the rivers that drain water into the lake. Samples were taken at 5 spots in Limboto Lake and 8 spots at the surrounding rivers. The rivers that flow into Limboto Lake and were made as samples consisted of Alo River (3 samples), Toyidito River (2 samples), Molamahu River (1 sample), Molalahu River (1 sample) and also Alopohu Dam (1 sample). Instruments used were $\mathrm{pH}$ meter and thermometer for physical parameters, and AAS for chemical parameters. Microbiology was measured using MPN method. The results of the analysis indicated that the water quality in Limboto Lake and the surrounding rivers were polluted. The parameters of nitrate, phosphate and hydrogen sulfide were above the standard stipulated by the Government Regulation Number 82 of 2001.
\end{abstract}

Keywords: BOD, COD, domestic waste, spatial distribution, TSS.

(Diterima: 19-03-2017; Disetujui: 14-09-2017)

\section{Pendahuluan}

Air merupakan sumber daya alam yang diperlukan untuk hajat hidup orang banyak, bahkan oleh semua makhluk hidup. Mengingat pentingnya sumber daya air ini, maka keberadaannya perlu dilindungi sehingga dapat dimanfaatkan oleh manusia serta makhluk hidup lainnya. Pengelolaan sumber daya air khususnya ekosistem Danau Limboto sangat penting diperhatikan, karena merupakan lokasi pariwisata, sumber budidaya perikanan, pertanian dan juga sebagai penampung air dari sungai-sungai di sekitarnya. Lihawa dan Sutikno (2009) mengemukakan bahwa Danau Limboto menampung sedimen dari sungai-sungai yang bermuara ke danau. Nisbah pelepasan sedimen DAS Alo-Pohu yang bermuara ke danau adalah 0.18. Nisbah pelepasan sedimen tertinggi adalah DAS Alo yaitu 0.59 . Hal ini menunjukkan $58.9 \%$ sedimen yang berasal dari DAS Alo bermuara ke Danau Limboto. Selain itu juga, terdapat aktivitas pertanian, perikanan, pariwisata serta pemukiman di bantaran danau yang menjadi sumber pencemar.

Pentingnya pemantauan kualitas air menurut (Effendi, 2003) yakni (1) untuk mendeteksi dan mengukur pengaruh yang ditimbulkan oleh suatu pencemar terhadap kualitas lingkungan dan mengetahui perbaikan kualitas lingkungan setelah pencemar dihilangkan; (2) mengetahui hubungan sebab dan akibat antara variabel ekologi dengan parameter fisika dan kimia untuk mendapatkan baku mutu kualitas air dan (3) mengetahui gambaran kualitas air pada suatu tempat secara umum. Selain itu juga interpretasi terhadap kualitas air sungai sangat penting, karena sungai merupakan ekosistem yang dinamis (Effendi, 2016). Mengingat pentingnya evaluasi kualitas air pada ekosistem Danau Limboto maka standar kualitasnya harus dipantau sesuai dengan standar baku mutu yang ditetapkan oleh pemerintah. Pentingnya dilakukan pemantauan kualitas air Danau Limboto disebabkan Danau Limboto merupakan produsen ikan air tawar di Daerah Gorontalo. Pulford et al. (2017) mengemukakan bahwa penting untuk melakukan pemantauan kualitas air danau, sebab danau sebagai penghasil ikan air tawar dan sarana rekreasi. Hal ini untuk mencegah terjadinya pencemaran pada perairan danau yang dapat mengganggu kelangsungan hidup ikan air tawar. Selain itu juga, penting untuk monitoring dan evaluasi kualitas air danau sebagai dasar dalam pengambilan kebijakan pengelolaan sumber daya air.

Penelitian ini bertujuan untuk mengevaluasi karakteristik kualitas air pada ekosistem Danau Limboto dan sungai-sungai disekitarnya sesuai dengan peruntukannya.

\section{Metode Penelitian}

Penelitian dilaksanakan di Danau Limboto dan sungai-sungai yang mengalirkan airnya ke danau tersebut. Lokasi sampel diambil 5 titik pada Danau Limboto dan 8 titik pada sungai-sungai disekitarnya. Sungai-sungai yang bermuara di Danau Limboto dan dijadikan sampel yakni Sungai Alo sebanyak 3 sampel, Sungai Toyidito sebanyak 2 sampel, Sungai Molamahu sebanyak 1 sampel, Sungai Molalahu sebanyak 1 sampel dan pada Bendung Alopohu sebanyak 1 sampel. Alat yang digunakan adalah water sampler untuk mengambil sampel air, $\mathrm{pH}$ meter dan thermometer untuk parameter fisik, serta AAS untuk parameter kimia. Pengukuran mikrobiologi dengan menggunakan metode MPN. Analisis parameter fisik dan kimia air dilakukan pada Balai Teknik Kesehatan Lingkungan 
dan Pengendalian Penyakit Kelas I Manado dan analisis mikrobiologi dilakukan pada Dinas Kesehatan Kabupaten Gorontalo. Baku mutu yang menjadi acuan adalah PP 82 Tahun 2001 Kelas II.

\section{Hasil dan Pembahasan}

\subsection{Kualitas Fisik dan Kimia Air Danau Limboto}

Hasil analisis menunjukkan bahwa parameter kimia kualitas air danau tidak memenuhi syarat baku mutu PP 82 Tahun 2001 Kelas II khususnya parameter hydrogen sulfida, nitrat dan fosfat. Hasil analisis kualitas fisik dan kimia air pada Danau Limboto ditunjukkan pada Tabel 1.

\section{a. Parameter Nitrat}

Nitrat pada Danau Limboto berkisar 9 - $34 \mathrm{mg} / \mathrm{l}$. Berdasarkan hasil ini maka konsentrasi nitrat berada di atas baku mutu yang ditetapkan oleh PP 82 Tahun 2001 Kelas II yaitu $10 \mathrm{mg} / \mathrm{l}$. Danau Limboto menerima masukan air dari sungai-sungai disekitarnya juga dijadikan sebagai lokasi budidaya ikan oleh masyarakat. Hal ini memicu tingginya nitrat di sungai selain karena pasokan dari daerah pertanian disekitarnya. Banyak faktor yang dapat mempengaruhi tingginya nitrat di danau. Indrayani et al (2015) menyebutkan bahwa tiap kilogram ikan peliharaan akan menghasilkan nitrat sebesar $0.13-0.21 \mathrm{~g} / \mathrm{hari}$. Hasil analisis nitrat dibandingkan dengan baku mutu ditunjukkan pada Gambar 1.

Tabel 1. Karakteristik kualitas fisik dan kimia air Danau Limboto

\begin{tabular}{|c|c|c|c|c|c|c|c|c|c|}
\hline \multirow[t]{2}{*}{ No } & \multirow[t]{2}{*}{ Parameter } & \multirow[t]{2}{*}{ Satuan } & \multicolumn{5}{|c|}{ Hasil Analisis } & \multirow{2}{*}{$\begin{array}{l}\text { Baku } \\
\text { Mutu }\end{array}$} & \multirow[t]{2}{*}{ Keterangan } \\
\hline & & & AD1 & AD2 & AD3 & AD4 & AD5 & & \\
\hline \multicolumn{10}{|l|}{ Posisi } \\
\hline A. & IKA & & & & & & & & \\
\hline 1 & Temperatur & ${ }^{\circ} \mathrm{C}$ & 23,2 & 23,5 & 23,3 & 23,1 & 23,3 & Dev 3 & Memenuhi \\
\hline 2 & TSS & $\mathrm{mg} / \mathrm{l}$ & 26,7 & 20,0 & 28,3 & 10,0 & 18,3 & 50 & Memenuhi \\
\hline \multicolumn{10}{|c|}{ KIMIA ANORGANIK } \\
\hline 1 & Khlorida $(\mathrm{Cl})$ & $\mathrm{mg} / \mathrm{l}$ & 25,50 & 24,23 & 24,48 & 111,19 & 19,89 & $(-)$ & Memenuhi \\
\hline 2 & $\mathrm{H}_{2} \mathrm{~S}$ & $\mathrm{mg} / \mathrm{l}$ & 0,199 & 0,186 & 0,049 & 0,145 & 0,327 & 0.002 & $\begin{array}{c}\text { Tidak } \\
\text { Memenuhi }\end{array}$ \\
\hline 3 & Besi (Fe) & $\mathrm{mg} / \mathrm{l}$ & 0,0826 & 0,0662 & 0,0471 & 0,0928 & 0,0477 & $(-)$ & Memenuhi \\
\hline 4 & $\mathrm{pH}$ & $\mathrm{mg} / \mathrm{l}$ & 7,9 & 7,7 & 8 & 7,7 & 7,7 & $6,0-9,0$ & Memenuhi \\
\hline 5 & Flourida (F) & $\mathrm{mg} / \mathrm{l}$ & 0,4 & 0,3 & 00,4 & 0,4 & 0,4 & 1,5 & Memenuhi \\
\hline 6 & Kadmium $(\mathrm{Cd})$ & $\mathrm{mg} / \mathrm{l}$ & $<\mathrm{LD}$ & $<\mathrm{LD}$ & $<\mathrm{LD}$ & $<\mathrm{LD}$ & $<\mathrm{LD}$ & 0,01 & Memenuhi \\
\hline 7 & Fosfat $\left(\mathrm{PO}_{4}\right)$ & $\mathrm{mg} / \mathrm{l}$ & 0,9 & 1,2 & 0,7 & 0,8 & 1,2 & 0,2 & $\begin{array}{c}\text { Tidak } \\
\text { Memenuhi }\end{array}$ \\
\hline 8 & Nitrat $\left(\mathrm{NO}_{3}\right)$ & $\mathrm{mg} / \mathrm{l}$ & 34 & 32 & 9 & 18 & 26 & 10 & $\begin{array}{c}\text { Tidak } \\
\text { Memenuhi }\end{array}$ \\
\hline 9 & Nitrit $\left(\mathrm{NO}_{2}\right)$ & $\mathrm{mg} / \mathrm{l}$ & 0,01 & 0,01 & 0,01 & 0,01 & 0,01 & 0,06 & Memenuhi \\
\hline 10 & COD & $\mathrm{mg} / \mathrm{l}$ & 3 & 3 & 3 & 3 & 3 & 25 & Memenuhi \\
\hline 11 & DO & $\mathrm{mg} / \mathrm{l}$ & 7 & 7 & 7 & 7 & 7 & $>4$ & Memenuhi \\
\hline 12 & $\mathrm{NH}_{3}-\mathrm{N}$ & $\mathrm{mg} / \mathrm{l}$ & 1,37 & 1,35 & 0,56 & 1,8 & 1,66 & $(-)$ & Memenuhi \\
\hline 13 & Arsen (As) & $\mathrm{mg} / \mathrm{l}$ & $<\mathrm{LD}$ & $<\mathrm{LD}$ & $<\mathrm{LD}$ & $<\mathrm{LD}$ & $<\mathrm{LD}$ & 1 & Memenuhi \\
\hline 14 & Tembaga $(\mathrm{Cu})$ & $\mathrm{mg} / \mathrm{l}$ & $<\mathrm{LD}$ & $<\mathrm{LD}$ & $<\mathrm{LD}$ & $<\mathrm{LD}$ & $<\mathrm{LD}$ & 0,02 & Memenuhi \\
\hline 15 & Timbal $(\mathrm{Pb})$ & $\mathrm{mg} / \mathrm{l}$ & $<\mathrm{LD}$ & $<\mathrm{LD}$ & $<\mathrm{LD}$ & $<\mathrm{LD}$ & $<\mathrm{LD}$ & 0,03 & Memenuhi \\
\hline 16 & Mangan (Mn) & $\mathrm{mg} / \mathrm{l}$ & 0,0888 & 0,1445 & 0,1527 & 0,0928 & 0,0955 & $(-)$ & Memenuhi \\
\hline 17 & Air Raksa (Hg) & $\mathrm{mg} / \mathrm{l}$ & $<\mathrm{LD}$ & $<\mathrm{LD}$ & $<\mathrm{LD}$ & $<\mathrm{LD}$ & $<\mathrm{LD}$ & 0,002 & Memenuhi \\
\hline 18 & Seng (Zn) & $\mathrm{mg} / \mathrm{l}$ & 0,01 & 0,03 & 0,02 & 0,01 & 0,01 & 0,05 & Memenuhi \\
\hline \multicolumn{10}{|c|}{ KIMIA ORGANIK } \\
\hline 19 & Minyak dan lemak & $\mathrm{mg} / \mathrm{l}$ & 1 & 1 & $<\mathrm{LD}$ & 1 & 1 & 1000 & Memenuhi \\
\hline
\end{tabular}

Konsentrasi nitrat di perairan Danau Limboto sangat tinggi jika dibandingkan dengan kadar nitrat di perairan Pulau Gangga yang berkisar $0.012-0.026 \mathrm{mg} / \mathrm{l}$ dengan nilai rata-rata $0.020 \pm 0.006 \mathrm{mg} / \mathrm{l}$. Kadar nitrat di perairan Pulau Siladen berkisar 0.001-0.005 mg/l dengan nilai rata-rata $0.003 \pm 0.002 \mathrm{mg} / \mathrm{l}$ (Arfah \& Patty, 2014).

Nitrat di alam dapat dihasilkan secara alami maupun dari aktivitas manusia. Sumber alami nitrat adalah dari siklus nitrogen sedangkan sumber yang berasal dari aktivitas manusia adalah penggunaan pupuk nitrogen, limbah industri dan limbah organik manusia (Setiowati dan Wahyuni, 2016). Jika manusia membuang kotoran dalam air, maka kadar nitrat akan meningkat. Kotoran banyak mengandung amoniak. Nitrat juga terdapat dalam pupuk buatan, jika digunakan dengan konsentrasi tinggi akan mengakibatkan pencemaran tanah (Sastrawijaya, 2009). Tingginya konsentrasi nitrat di Danau Limboto karena penggunaan pupuk oleh masyarakat dan buangan limbah domestik masyarakat yang bermukim di bantaran danau. Pakan ikan pada karamba jaring apung di Danau Limboto juga dapat menambah jumlah nitrat dan fosfor di danau. Hasil penelitian menunjukkan bahwa $70 \%$ nitrogen yang dikonsumsi oleh ikan akan terbuang ke perairan (pakan yang digunakan konversi ratio 1.6). Hal ini juga menghasilkan total fosfor di perairan Danau Toba setiap hari sebesar 2.39 ton untuk pakan jenis 1 dan sebanyak 2.15 ton untuk pakan jenis 2 dengan asumsi $5 \%$ pakan tidak terkonsumsi oleh ikan (Panjaitan, 2009). 


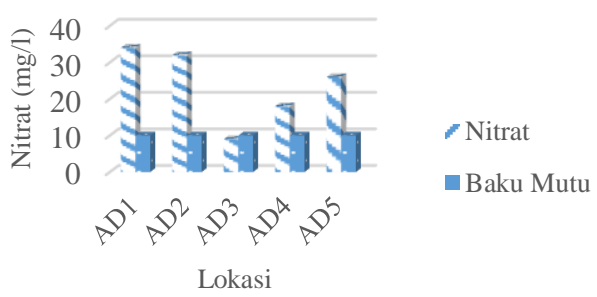

Gambar 1. Hasil analisis nitrat di Danau Limboto

\section{b. Parameter Fosfat}

Fosfor merupakan salah satu bahan kimia yang sangat penting bagi makhluk hidup. Fosfor terdapat di alam dalam dua bentuk yaitu senyawa fosfat organik dan senyawa fosfat anorganik. Fosfat terdapat di air alam atau air limbah sebagai senyawa orthofosfat, polifosfat dan fosfat organik. Di daerah pertanian ortofosfat berasal dari bahan pupuk yang masuk ke sungai atau danau melalui drainase aliran hujan. Tingginya fosfat di Danau Limboto dapat disebabkan oleh sungai-sungai yang bermuara di Danau Limboto memiliki fosfat di atas baku mutu yang ditetapkan. Daerah penelitian merupakan daerah pertanian sehingga adanya fosfat dapat berasal dari pemupukan lahan pertanian dan perkebunan masyarakat. Fosfor bersifat kritis karena secara umum merupakan hara yang terbatas dalam ekosistem. Fosfor terlarut dari mineral-mineral fosfat dan sumber-sumber lainnya seperti fosfat, diserap oleh tanaman dan tergabung dalam asam nukleat yang menyusun material genetik dalam organisme. Mineralisasi dari biomassa oleh pembusukan penguraian mikroba mengembalikan fosfor kepada larutan garamnya yang kemudian mengendap sebagai bahan murni (Effendi, 2003).

Air biasanya mengandung fosfat anorganik terlarut. Fitoplankton dan tanaman lain akan mengabsorbsi fosfat dan membentuk senyawa misalnya adenosine trifospat. Fosfor memasuki air melalui berbagai jalan: kotoran limbah, sisa pertanian, kotoran hewan dan sisa tanaman dan hewan yang mati. Sisa pertanian juga mengandung fosfor tetapi jumlahnya tidak banyak. Tanah dapat mengikat senyawa fosfat sehingga tidak banyak terlarut. Jika terjadi erosi maka butir tanah dan fosfat akan hanyut ke sungai (Sastrawijaya, 2009).

Fosfat berkisar 0,8 - 1,2 mg/l (Gambar 2). Hasil ini masih lebih tinggi jika dibandingkan dengan penelitian yang dilakukan oleh Arfah \& Patty (2014) yakni fosfat berkisar $0.005-0.011 \mathrm{mg} / \mathrm{l}$ dengan rata-rata $0.008 \pm$ $0.003 \mathrm{mg} / \mathrm{l}$. Berdasarkan hasil ini maka parameter fosfat di Danau Limboto berada di atas baku mutu yang ditetapkan oleh PP 82 Tahun 2001 yakni sebesar 0.2 $\mathrm{mg} / \mathrm{l}$. Kondisi yang tinggi diakibatkan oleh pertanian, peternakan dan juga berasal dari budidaya ikan dalam jaring apung yang berasal dari penggunaan pakan ikan. Danau Limboto juga dimanfaatkan oleh masyarakat sebagai lokasi budidaya ikan. Hal ini dapat memicu tingginya forfat di perairan. Penelitian Tatangindatu et al. (2013) menunjukkan bahwa fosfat juga dihasilkan berasal dari sisa pakan pellet yang terbuang. Pakan pellet yang diberikan kepada ikan tidak semua disantap oleh ikan, sebagian hanyut terbawa arus dan turbulensi air yang disebabkan oleh pergerakan ikan saat berebut makanan. Hancuran pellet biasanya terikut pada saat pemberian pakan dan hancuran yang berukuran kecil tersebut tidak ditangkap oleh ikan dan terbawa arus. Hal ini menyebabkan tingginya total fosfat di danau. Keberadaan fosfor secara berlebihan yang disertai dengan keberadaan nitrogen dapat menstimulir ledakan pertumbuhan algae di perairan (algae bloom). Algae yang melimpah dapat membentuk lapisan permukaan air, yang selanjunya dapat menghambat penetrasi oksigen dan cahaya matahari sehingga kurang menguntungkan bagi ekosistem perairan.

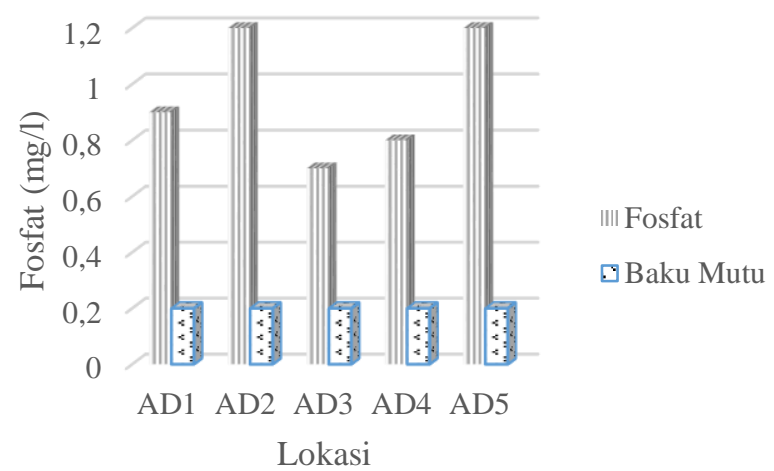

Gambar 2. Hasil analisis fospat pada Danau Limboto

\section{c. $\quad$ Parameter Hidrogen Sulfida $\left(\mathrm{H}_{2} \mathrm{~S}\right)$}

Hidrogen sulfida $\left(\mathrm{H}_{2} \mathrm{~S}\right)$ di Danau Limboto berkisar 0.049 - $0.327 \mathrm{mg} / \mathrm{l}$. Berdasarkan hasil ini maka parameter $\mathrm{H}_{2} \mathrm{~S}$ pada air Danau Limboto sudah berada di atas baku mutu yang ditetapkan yakni $0.002 \mathrm{mg} / \mathrm{l}$. Hasil analisis $\mathrm{H}_{2} \mathrm{~S}$ ditunjukkan pada Gambar 3 .

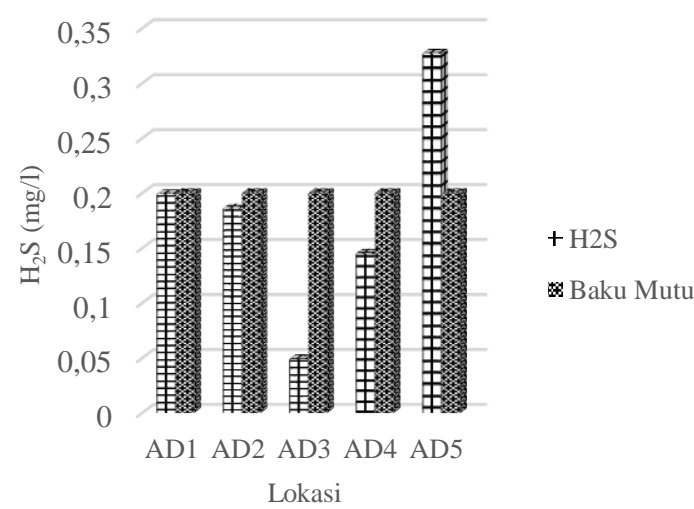

Gambar 3. Hasil analisis $\mathrm{H}_{2} \mathrm{~S}$ pada Danau Limboto

Hasil ini sudah sangat tinggi jika dibandingkan dengan penelitian Purnomo et a.l (2013), konsentrasi $\mathrm{H}_{2} \mathrm{~S}$ di kawasan perairan terbuka pada kawasan tutupan enceng gondok di Rawa Pening berkisar 0.009-0.014 
$\mathrm{mg} / \mathrm{l}$ dan pada kawasan tutupan enceng gondok berkisar $0.006-0.015 \mathrm{mg} / \mathrm{l}$.

\subsection{Kualitas Fisik dan Kimia Air Sungai}

Parameter $\mathrm{H}_{2} \mathrm{~S}$, nitrat dan fosfat berada di atas baku mutu yang ditetapkan oleh PP 82 Tahun 2001. Hasil analisis kualitas air fisik dan kimia di sungai yang bermuara di Danau Limboto ditunjukkan pada Tabel 3.

Tabel 2. Hasil analisis kualitas air sungai

\begin{tabular}{|c|c|c|c|c|c|c|c|c|c|c|c|c|}
\hline \multirow{2}{*}{ No } & \multirow{2}{*}{ Parameter } & \multirow{2}{*}{ Satuan } & \multicolumn{8}{|c|}{ Hasil Analisis } & \multirow{2}{*}{$\begin{array}{l}\text { Baku } \\
\text { Mutu }\end{array}$} & \multirow{2}{*}{ Ket } \\
\hline & & & AL1 & AL2 & AL3 & AL4 & AL5 & AL6 & AL7 & AL8 & & \\
\hline A. & FISIKA & & & & & & & & & & & \\
\hline 1 & Temperatur & ${ }^{\circ} \mathrm{C}$ & 2.5 & 23.3 & 23.5 & 23.6 & 23.7 & 23.2 & 23.2 & 23.3 & Dev 3 & MS \\
\hline 2 & TSS & $\mathrm{mg} / \mathrm{l}$ & 15.0 & 16.7 & 26.7 & 20.0 & 18.3 & 13.3 & 15.0 & 16.7 & 50 & MS \\
\hline B. & \multicolumn{12}{|c|}{ KIMIA ANORGANIK } \\
\hline 1 & Khlorida $(\mathrm{Cl})$ & $\mathrm{mg} / \mathrm{l}$ & 20.40 & 21.68 & 21.42 & 21.42 & 19.89 & 20.91 & 26.8 & 23.46 & $(-)$ & MS \\
\hline 2 & $\begin{array}{l}\text { Hidrogen } \\
\text { Sulfida }\left(\mathrm{H}_{2} \mathrm{~S}\right)\end{array}$ & $\mathrm{mg} / \mathrm{l}$ & 0.506 & 0.497 & 0.397 & 0.266 & 0.145 & 0.321 & 0.326 & 0.209 & 0.002 & TMS \\
\hline 3 & Besi $(\mathrm{Fe})$ & $\mathrm{mg} / \mathrm{l}$ & 0.0147 & 0.0239 & 0.0334 & 0.042 & 0.053 & 0.067 & 0.0437 & 0.067 & $(-)$ & MS \\
\hline 4 & $\mathrm{pH}$ & $\mathrm{mg} / \mathrm{l}$ & 7.7 & 7.8 & 7.6 & 7.7 & 6.8 & 7.8 & 7.7 & 7.8 & $6.0-9.0$ & MS \\
\hline 5 & Flourida (F) & $\mathrm{mg} / \mathrm{l}$ & 0.1 & 0.7 & 0.6 & 0.7 & 0.3 & 0.3 & 0.4 & 0.4 & 1.5 & MS \\
\hline 6 & Kadmium $(\mathrm{Cd})$ & $\mathrm{mg} / \mathrm{l}$ & $<\mathrm{LD}$ & $<\mathrm{LD}$ & $<\mathrm{LD}$ & $<\mathrm{LD}$ & $<\mathrm{LD}$ & $<\mathrm{LD}$ & $<\mathrm{LD}$ & $<\mathrm{LD}$ & 0.01 & MS \\
\hline 7 & Fosfat $\left(\mathrm{PO}_{4}\right)$ & $\mathrm{mg} / \mathrm{l}$ & 1.0 & 1.3 & 0.7 & 1.3 & 1.1 & 1.4 & 1.6 & 1.2 & 0.2 & TMS \\
\hline 8 & Nitrat $\left(\mathrm{NO}_{3}\right)$ & $\mathrm{mg} / \mathrm{l}$ & 114 & 83 & 88 & 62 & 33 & 67 & 62 & 40 & 10 & TMS \\
\hline 9 & Nitrit $\left(\mathrm{NO}_{2}\right)$ & $\mathrm{mg} / \mathrm{l}$ & 0.03 & 0.04 & 0.02 & 0.02 & 0.02 & 0.02 & 0.02 & 0.01 & 0.06 & MS \\
\hline 10 & COD & $\mathrm{mg} / \mathrm{l}$ & 3 & 3 & 3 & 3 & 4 & 4 & 4 & 3 & 25 & MS \\
\hline 11 & DO & $\mathrm{mg} / \mathrm{l}$ & 7 & 7 & 7 & 7 & 7 & 7 & 7 & 7 & $>4$ & MS \\
\hline 12 & $\mathrm{NH}_{3}-\mathrm{N}$ & $\mathrm{mg} / \mathrm{l}$ & 2.93 & 2.79 & 2.24 & 1.84 & 1.15 & 2.3 & 2.06 & 1.57 & $(-)$ & MS \\
\hline 13 & Arsen (As) & $\mathrm{mg} / \mathrm{l}$ & $<\mathrm{LD}$ & $<\mathrm{LD}$ & $<\mathrm{LD}$ & $<\mathrm{LD}$ & $<\mathrm{LD}$ & $<\mathrm{LD}$ & $<\mathrm{LD}$ & $<\mathrm{LD}$ & 1 & MS \\
\hline 14 & Tembaga $(\mathrm{Cu})$ & $\mathrm{mg} / \mathrm{l}$ & $<\mathrm{LD}$ & $<\mathrm{LD}$ & $<\mathrm{LD}$ & $<\mathrm{LD}$ & $<\mathrm{LD}$ & $<\mathrm{LD}$ & $<\mathrm{LD}$ & $<\mathrm{LD}$ & 0,02 & MS \\
\hline 15 & Timbal $(\mathrm{Pb})$ & $\mathrm{mg} / \mathrm{l}$ & $<\mathrm{LD}$ & $<\mathrm{LD}$ & $<\mathrm{LD}$ & $<\mathrm{LD}$ & $<\mathrm{LD}$ & $<\mathrm{LD}$ & $<\mathrm{LD}$ & $<\mathrm{LD}$ & 0,03 & MS \\
\hline 16 & Mangan (Mn) & $\mathrm{mg} / \mathrm{l}$ & 0.1237 & 0.1147 & 0.1024 & 0.1138 & 0.144 & 0.153 & 0.1171 & 0.099 & $(-)$ & MS \\
\hline 17 & Air Raksa (Hg) & $\mathrm{mg} / \mathrm{l}$ & $<\mathrm{LD}$ & $<\mathrm{LD}$ & $<\mathrm{LD}$ & $<\mathrm{LD}$ & $<\mathrm{LD}$ & $<\mathrm{LD}$ & $<\mathrm{LD}$ & $<\mathrm{LD}$ & 0.002 & MS \\
\hline 18 & Seng $(\mathrm{Zn})$ & $\mathrm{mg} / \mathrm{l}$ & 0.01 & 0.01 & 0.01 & 0.01 & 0.01 & 0.02 & 0.01 & 0.02 & 0.05 & MS \\
\hline C. & \multicolumn{12}{|c|}{ KIMIA ORGANIK } \\
\hline 19 & $\begin{array}{l}\text { Minyak dan } \\
\text { lemak }\end{array}$ & $\mathrm{mg} / \mathrm{l}$ & 1 & 1 & 1 & 1 & 1 & & 1 & $<\mathrm{LD}$ & 1000 & MS \\
\hline
\end{tabular}

Catatan: AL1: Bendung Alopohu; AL2: Jembatan Sungai Alo; AL3: Sungai Alo; AL4 dan AL6 Sungai Tayidito; AL5: Sungai Alo;

AL7: Sungai Molalahu; AL8: Sungai Molamahu; MS = memenuhi syarat; TMS = tidak memenuhi syarat.

Sumber: Data Primer 2016

\section{a. Parameter Nitrat}

Nitrat merupakan salah satu bentuk nitrogen yang larut dalam air. Pencemaran dapat berasal dari pemupukan, kotoran hewan dan manusia menyebabkan tingginya nitrat di sungai atau danau. Hasil analisis nitrat pada air sungai berkisar 33-114 mg/l. Berdasarkan hasil ini maka konsentrasi nitrat berada di atas baku mutu yang ditetapkan oleh PP 82 Tahun 2001 Kelas II sebesar $10 \mathrm{mg} / \mathrm{l}$. Nitrat pada sungai ini sudah sangat tinggi jika dibandingkan dengan penelitian Purnomo et al., (2013) dimana konsentrasi nitrat pada Rawa Pening hanya berkisar $0.106-0.236 \mathrm{mg} / \mathrm{l}$ pada kawasan terbuka dan tertutup enceng gondok berkisar 0.088-0.279 mg/l. Medudhula et al. (2012) menunjukkan konsentrasi Nitrat pada waduk di Daerah Karimnagar Amdhra Pradesh berkisar 0.01-0.03 mg/l. Pujiastuti et al. (2013) menunjukkan bahwa konsentrasi nitrat tertinggi sebesar $3.32 \mathrm{mg} / \mathrm{l}$. Hasil ini lebih rendah dibandingkan dengan kandungan nitrat yang berada di Danau Limboto. Kadar nitrat pada Danau Tondano sebesar $0.5 \mathrm{mg} / \mathrm{l}$ juga lebih rendah dibandingkan dengan nitrat di Danau Limboto. Kadar nitrat lebih dari $0.2 \mathrm{mg} / \mathrm{l}$ dapat menyebabkan terjadinya eutrofikasi selanjutnya dapat menyebabkan blooming sekaligus merupakan faktor pemicu bagi pesatnya pertumbuhan tumbuhan fitoplankton dan tumbuhan air lainnya
(Tatangindatu et al., 2013). Effendi et al. (2015) menunjukkan bahwa kandungan Nitrat di Sungai Ciambulawung Banten hanya berkisar 0.04 hingga 0.29 $\mathrm{mg} / \mathrm{l}$. Hasil analisis nitrat dibandingkan dengan baku mutu ditunjukkan pada Gambar 4.

\section{b. Parameter Fosfat}

Fosfat di sungai berkisar $0.7-1.6 \mathrm{mg} / \mathrm{l}$. Berdasarkan hasil ini maka parameter fosfat berada di atas baku mutu yang ditetapkan oleh PP 82 Tahun 2001 yakni sebesar $0.2 \mathrm{mg} / \mathrm{l}$. Kadar fosfat pada sungai ditunjukkan pada Gambar 5.

Tingginya kadar fosfat di perairan disebabkan daerah Kabupaten Gorontalo merupakan daerah pertanian. Sumber utama penyebab peningkatan fosfor dan nitrogen adalah aktivitas pertanian yang menggunakan pupuk dalam jumlah besar. Hilangnya unsur hara dari daerah pertanian dan masuknya unsur hara ke perairan terjadi melalui tiga cara yakni drainase, erosi tanah pucuk dan eksresi dari hewan peliharaan (Mason, 1993 dalam Effendi, 2003). 


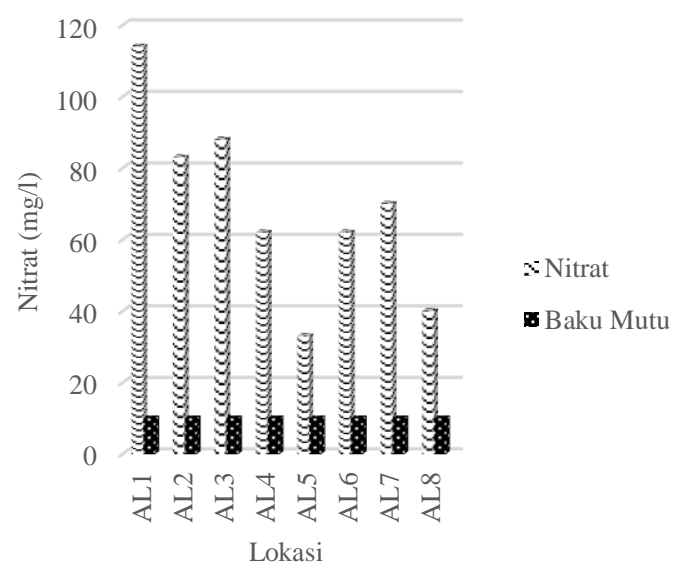

Gambar 4. Hasil analisis nitrat

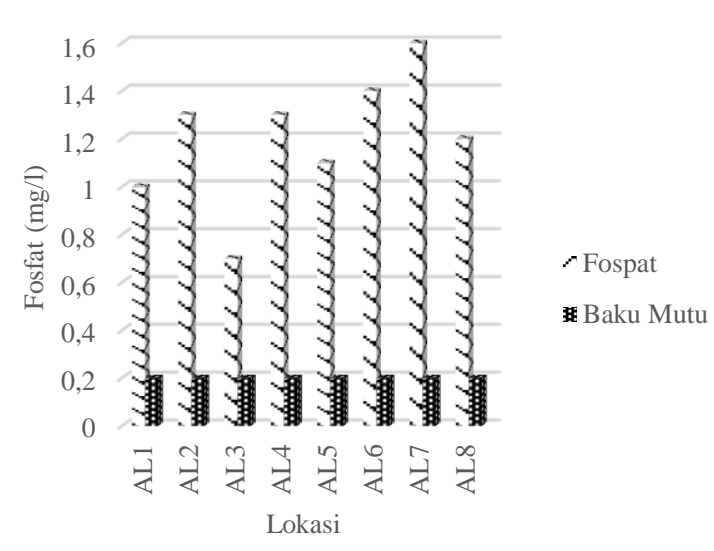

Gambar 5. Hasil analisis parameter fosfat

\section{c. Parameter Hidrogen Sulfida $\left(\mathrm{H}_{2} \mathrm{~S}\right)$}

Di perairan sulfur berikatan dengan ion hidrogen dan oksigen. Beberapa bentuk sulfur diperairan adalah sulfida $\left(\mathrm{S}^{2-}\right)$, hidrogen sulfida $\left(\mathrm{H}_{2} \mathrm{~S}\right)$, ferro sulfida $(\mathrm{FeS})$, sulfur dioksida $\left(\mathrm{SO}_{2}\right)$, sulfida $\left(\mathrm{SO}_{3}\right)$ dan sulfat ( $\left.\mathrm{SO}_{4}\right)$ (Effendi, 2003). $\mathrm{H}_{2} \mathrm{~S}$ dapat menimbulkan permasalahan yakni mudah larut, toksik dan menimbulkan bau seperti telur busuk.

$\mathrm{H}_{2} \mathrm{~S}$ pada air sungai berkisar $0.209-0.506 \mathrm{mg} / \mathrm{l}$ (Gambar 6). Hasil ini telah berada di atas bakumutu yang ditetapkan oleh PP 82 Tahun 2001 dimana disyaratkan tidak melebihi $0.002 \mathrm{mg} / \mathrm{l}$.

\section{d. Parameter Mikrobiologis Air Danau dan Air Sungai}

Parameter mikrobiologi yang diukur baik pada Danau Limboto maupun sungai-sungai di sekitarnya adalah total Coliform dan E.coli. Bakteri Coliform dapat digunakan sebagai indikator adanya pencemaran feses atau kotoran manusia dan hewan di dalam perairan. Golongan bakteri ini umumnya terdapat dalam fase manusia dan hewan (Suriawiara, 1996).

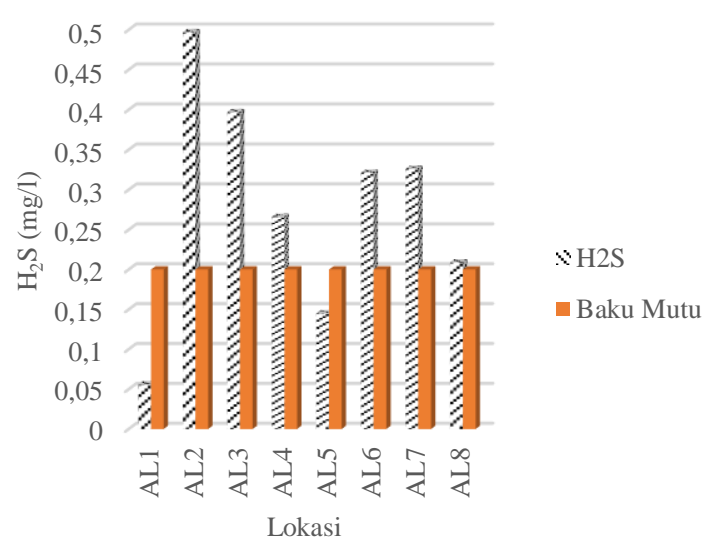

Gambar 6. Hasil analisis $\mathrm{H}_{2} \mathrm{~S}$ di sungai

Coliform rata-rata di Danau Limboto sebanyak 2400 MPN/100 ml. Hasil ini masih berada di bawah baku mutu yang ditetapkan oleh PP 82 Tahun 2001 tidak melebihi 5000 MPN/100 ml. Hasil total Coliform yang rata-rata $2400 \mathrm{MPN} / 100 \mathrm{ml}$ lebih tinggi jika dibandingkan dengan nilai Coliform pada outlet Danau Pondok Lapan yang berkisar 480.9-839.5 MPN/100 ml (Rizki et al, 2015). Kehadiran mikroba patogen di dalam air akan meningkat jika jumlah kandungan bahan organik di dalam air cukup tinggi. Sumber total Coliform di Danau Limboto berasal dari pemukiman masyarakat di bantaran danau. Limbah domestik dan limbah pertanian masyarakat dapat masuk ke Danau Limboto secara langsung atau terbawa masuk ke sungai dan masuk ke danau.

E.coli di Danau Limboto berkisar 46-1100 MPN/100 ml (Tabel 4). Berdasarkan hasil ini kualitas air danau cenderung telah berada di atas baku mutu yang ditetapkan yakni tidak melebihi 1000 MPN/100 $\mathrm{ml}$.

\begin{tabular}{lccccc}
\multicolumn{3}{c}{ Tabel 4. Hasil analisis mikrobiologis air Danau Limboto } \\
\cline { 2 - 5 } Lokasi & \multicolumn{3}{c}{ Parameter (MPN/100 ml) } & Keterangan \\
\cline { 2 - 5 } & Coliform & $\begin{array}{c}\text { Baku } \\
\text { Mutu }\end{array}$ & E.Coli & $\begin{array}{c}\text { Baku } \\
\text { Mutu }\end{array}$ & Memenuhi \\
\hline AD1 & 2400 & 5000 & 110 & 1000 & Memenuhi \\
\hline AD2 & 2400 & 5000 & 46 & 1000 & Memenuhi \\
\hline AD3 & 2400 & 5000 & 350 & 1000 & Memenuhi \\
\hline AD4 & 2400 & 5000 & 150 & 1000 & Memenuhi \\
\hline AD5 & 2400 & 5000 & 1100 & 1000 & $\begin{array}{l}\text { Tidak } \\
\text { Memenuhi }\end{array}$ \\
\hline
\end{tabular}

Sumber: Data Primer 2016

Golongan bakteri Coli merupakan jasad indikator di dalam substrat air, bahan makanan dan sebagainya untuk kehadiran jasad berbahaya. Escherichia sebagai salah satu contoh terkenal mempunyai beberapa spesies hidup di dalam saluran pencernaan makanan manusia dan hewan berdarah panas (Suriawira, 1996). Adanya E.coli pada perairan danau mengindikasikan bahwa air Danau Limboto sudah terdeteksi adanya pencemaran buangan limbah rumah tangga khususnya buangan tinja manusia. Masyarakat yang bermukim di sekitar danau membuang limbahnya langsung ke danau. Hal ini 
ditunjukkan dengan besarnya E.coli yang sudah berada di atas baku mutu yang ditetapkan.

Hasil analisis E.coli di Danau Limboto berkisar 46 $1100 \mathrm{MPN} / 100 \mathrm{ml}$ ini cenderung sama dengan penelitian Pujiastuti et al. (2013) di Perairan Gajah Mungkur dimana Coliform berkisar 110->2400 sel/100 ml. Berdasarkan hasil ini maka perairan Danau Limboto telah tercemar baik oleh feses ikan, feses manusia dan kotoran hewan. Adanya bakteri total Coliform maupun E.coli menandakan bahwa Danau Limboto telah terkontaminasi limbah domestik di sekitar danau.

\subsection{Kualitas Air Sungai}

Hasil analisis parameter mikrobiologi pada sungaisungai yang bermuara di Danau Limboto menunjukkan bahwa total Coliform rata-rata $2400 \mathrm{MPN} / 100 \mathrm{ml}$. Hasil ini masih berada di bawah baku mutu yang ditetapkan yakni 5000 MPN/100 ml. Parameter E.coli berkisar 2-9 MPN/100 ml. Hasil ini masih berada di bawah baku mutu yang ditetapkan oleh PP 82 Tahun 2001 Kelas II yakni $1000 \mathrm{MPN} / 100 \mathrm{ml}$. Hasil analisis mikrobiologi kualitas air sungai ditunjukkan pada Tabel 4.

Tabel 4. Hasil analisis mikrobiologi air sungai

\begin{tabular}{lccccc}
\hline \multirow{2}{*}{ Lokasi } & \multicolumn{3}{c}{ Parameter (MPN/100 ml) } & \\
\cline { 2 - 5 } & Coliform & $\begin{array}{l}\text { Baku } \\
\text { Mutu }\end{array}$ & E.Coli & $\begin{array}{c}\text { Baku } \\
\text { Mutu }\end{array}$ & \\
\hline AL1 & 2400 & 5000 & 9 & 1000 & Memenuhi \\
\hline AL2 & 2400 & 5000 & 5 & 1000 & Memenuhi \\
\hline AL3 & 2400 & 5000 & 2 & 1000 & Memenuhi \\
\hline AL4 & 2400 & 5000 & 2 & 1000 & Memenuhi \\
\hline AL5 & 2400 & 5000 & 0 & 1000 & Memenuhi \\
\hline AL6 & 2400 & 5000 & 0 & 1000 & Memenuhi \\
\hline AL7 & 2400 & 5000 & 0 & 1000 & Memenuhi \\
\hline AL8 & 2400 & 5000 & 0 & 1000 & Memenuhi \\
\hline Sunnnnnn
\end{tabular}

Sumber: Data Primer 2016

Catatan: AL1: Bendung Alopohu; AL2: Jembatan Sungai Alo; AL3: Sungai Alo; AL4 dan AL6: Sungai Toyidito; AL5: Sungai Alo; AL7: Sungai Molalahu; AL8: Sungai Molamahu.

Kehadiran total Coliform dan E.coli dalam perairan sungai menandakan adanya buangan feses manusia atau hewan berdarah panas ke badan air. Tingginya Coliform dan E.coli pada limbah domestik perlu diwaspadai, mengingat E.coli dan coliform merupakan salah satu indikator bahwa air tersebut telah terkandung bakteri patogen. Hal ini sesuai dengan pendapat Rand et al., 1975 dalam (Sumantri \& Cordova, 2011) bahwa bila kandungan E.coli telah mencapai $1000 \mathrm{sel} / 100 \mathrm{ml}$ besar kemungkinan pada air tersebut terdapat bakteri patogen, sehingga mengancam kesehatan manusia. Hal ini karena adanya bakteri ini akan menimbulkan adanya bakteri lainnya.

\section{Kesimpulan}

Hasil analisis menunjukkan bahwa kualitas air Danau Limboto maupun sungai-sungai yang berada di sekitarnya telah tercemar. Parameter nitrat, fosfat dan hidrogen sulfida telah berada di atas baku mutu yang ditetapkan oleh PP 82 Tahun 2001. Kadar nitrat pada
Danau Limboto berkisar 9-34 mg/l dan pada sungasungai disekitarnya berkisar 33-114 mg/l. Berdasarkan hasil ini maka konsentrasi nitrat berada di atas baku mutu yang ditetapkan oleh PP 82 Tahun 2001 Kelas II sebesar $10 \mathrm{mg} / \mathrm{l}$. Kadar fosfat di Danau Limboto berkisar 0,8-1,2 mg/l dan di sungai sekitarnya berkisar 0,7-1,6 mg/l dan sungai berkisar 0,209-0,506 mg/l. Berdasarkan hasil ini maka parameter fosfat di Danau Limboto berada di atas baku mutu yang ditetapkan oleh PP 82 Tahun 2001 yakni sebesar 0,2 mg/l. Hasil analisis Coliform rata-rata di Danau Limboto dan sungai ratarata $2400 \mathrm{MPN} / 100 \mathrm{ml}$. Hasil ini masih berada di bawah baku mutu yang ditetapkan oleh PP 82 Tahun 2001 tidak melebihi $5000 \mathrm{MPN} / 100 \mathrm{ml}$. Hasil analisis E.coli berkisar 46-1100 MPN/100 ml dan di sungai sekitarnya berkisar 2-9 MPN/100 ml. Berdasarkan hasil ini maka kandungan E.coli di perairan Danau Limboto cenderung telah berada di atas baku mutu yang ditetapkan yakni tidak melebihi 1000 MPN/100 $\mathrm{ml}$.

\section{Daftar Pustaka}

[1] Arfah, H., S.I., 2014. Karakteristik Fosfat, Nitrat dan Oksigen terlarut di Perairan Pulau Gangga dan Pulau Siladen Sulawesi Utara. Jurnal Ilmiah Platax. 74-84.

[2] Effendi, H., 2003. Telaah kualitas air. Bagi pengelolaan sumber daya dan lingkungan perairan. Yogyakarta, Kanisius.

[3] Effendi, H., 2016. River Water Quality Preliminary Rapid Assessment Using Pollution Index. Procedia Environmental Sciences. pp. 562-567.

[4] Effendi, H., Romanto, \& Y. Wardiatno, 2015. Water quality status of Ciambulawung River, Banten Province, based on pollution indeks and NSF-WQI. Procedia Environmental Sciences, pp. 228-237.

[5] Indrayani, E., K. H. Nitimulyo, S. Hadisutanto, dan Rustadi, 2015. Analisis Kandungan Nitrogen, Fosfor dan Karbon Organik di Danau Sentani Papua. Jurnal Manusia dan Lingkungan, pp. 217-225.

[6] Lihawa, F., dan Sutikno, 2009. The Effect of watershed environmental conditions and landuse of sediment yield in Alo-Pohu watershed. Indonesia Journal of Geography. IJG, pp. 103-122.

[7] Medudhula, T., Ch. Samatha, dan C. Sammaiah, 2012. Analysis of water quality using physico-chemical parameters in lower manair reservoir of Karimnagar district, Andhra Pradesh. International Journal of Environmental Sciences, pp. 172-180.

[8] Panjaitan, P., 2009. Kajian potensi pencemaran karamba jaring apung PT. Aquafarm Nusantara di ekosistem perairan Danau Toba. pp. 290-300.

[9] Pujiastuti, P., B. Ismail, Pranoto, 2013. Kualitas dan beban pencemaran perairan Waduk Gajah Mungkur. Jurnal Ekosains. pp. 50-62.

[10] Pulford, E., B. Polidoro, M. Nation, 2017. Understanding, the relationships between water quality, recreational, fishing practices, and human health in Phoenix, Arizona. Journal of Environmental Management, pp. 242-250.

[11] Purnomo, P. W., M. Nitisupardjo, Y. Purwandari, 2013. Hubungan antara total bakteri dengan bahan organik, $\mathrm{NO}_{3}$ dan $\mathrm{H}_{2} \mathrm{~S}$ pada lokasi sekitar enceng gondok dan perairan terbuka di Rawa Pening. Retrieved from Journal of Management of Aquatic Resources: http://ejournal:s1.undip.ac.id/index.php/maquares

[12] Rizki, A., Y. Djayus, A Muhtadi, 2015. Analisis kualitas air dan beban pencemaran di Danau Pondok Lapan Kecamatan Salapian Kabupaten Langkat. Jurnal Aquacoastmarine. 9(4), pp. 57-66.

[13] Sastrawijaya, A., 2009. Pencemaran lingkungan. Jakarta, Rineka Cipta. 
ISSN 2086-4639 | e-ISSN 2460-5824ＪPSL Vol. 7 (3): 260-266

[14] Setiowati, R., dan E. Tri Wahyuni, 2016. Monitoring kadar Nitrit dan Nitrat pada air sumur di daerah Catur Tunggal Yogyakarta dengan Metode Spctrofotometris UV VIS. Jurnal Manusia dan Lingkungan. pp. 143-148.

[15] Sumantri, A., dan M. R. Cordova, 2011. Dampak limbah domestik perumahan skala kecil terhadap kualitas air ekosistem penerimanya dan dampaknya terhadap kesehatan masyarakat. JPSL. 1(2), pp. 127-134.
[16] Suriawiara, U., 1996. Mikrobiologi air dan dasar-dasar pengolahan buangan secara biologis. Bandung: Alumni.

[17] Tatangindatu, E., O. Kalesaran, dan R. Rompas, 2013. Studi parameter fisika kimia air pada areal budidaya ikan di Danau Tondano Desa Paleloan Kabupaten Minahasa. Jurnal Budidaya Perairan. pp. 8 - 19. 